\title{
Level of Organochlorine Pesticide in Prediabetic and Newly Diagnosed Diabetes Mellitus Patients with Varying Degree of Glucose Intolerance and Insulin Resistance among North Indian Population
}

\author{
Shipra Tyagi ${ }^{1}$, Brijesh Kumar Mishra ${ }^{2}$, Tusha Sharma ${ }^{3}$, Neha Tawar ${ }^{3}$, Abdul Jamil Urfi ${ }^{1}$, Basu Dev Banerjee ${ }^{3}$, Sri Venkata Madhu ${ }^{2}$ \\ ${ }^{1}$ Department of Environmental Studies, University of Delhi (North Campus), Delhi, \\ ${ }^{2}$ Department of Endocrinology, University College of Medical Sciences, University of Delhi, Delhi, \\ ${ }^{3}$ Environmental Biochemistry and Molecular Biology Laboratory, Department of Biochemistry, University College of Medical Sciences, University of Delhi, \\ Delhi, India
}

Background: Organochlorine pesticides (OCPs) exposure may induce an endocrine disruption which may lead to the risk of developing diabetes through alteration and disturbance of glucose metabolism, insulin resistance, and destruction of $\beta$-cells. The present study determines the recent trend of OCPs residue in blood samples and their association with the known risk factors responsible for developing the risk of diabetes among the North Indian population.

Methods: Blood sample of 300 patients (100 each of normal glucose tolerance [NGT], prediabetes and newly detected diabetes mellitus $[\mathrm{DM}])$ between the age group of 30 to 70 years were collected. OCPs residue in whole blood samples was analyzed by using gas chromatography equipped with a ${ }^{63} \mathrm{Ni}$ selective electron capture detector.

Results: Significantly higher levels of $\beta$-hexachlorocyclohexane (HCH), dieldrin, and p,p'-dichloro-diphenyl-dichloroethylene (DDE) were found in the prediabetes and newly detected DM groups as compared to NGT group. Insulin resistance showed to be significantly positive correlation with $\beta-\mathrm{HCH}$ and dieldrin. Also, fasting and postprandial glucose levels were significantly positively correlated with levels of $\beta-\mathrm{HCH}$, dieldrin, and p,p'-DDE. Further, when OCPs level was adjusted for age and body mass in$\operatorname{dex}(\mathrm{BMI})$, it was found that $\beta-\mathrm{HCH}$, dieldrin, and p,p'-DDE levels in blood increases the risk of diabetes by 2.70, 2.83, and 2.55 times respectively. Moreover, when we adjust OCPs level based on BMI categories (BMI $<23, \geq 23$, and $\leq 25$, and $\left.>25 \mathrm{~kg} / \mathrm{m}^{2}\right)$; $\beta$-HCH and p,p'-DDE showed a significant risk of developing newly detected DM with BMI $>25$ and $\geq 23$ and $\leq 25 \mathrm{~kg} / \mathrm{m}^{2}$.

Conclusion: The OCPs level present in the environment may be responsible for biological, metabolic, and endocrine disruptions within the human body which may increase the risk of developing newly detected DM. Hence, OCPs exposure can play a crucial role in the etiology of diabetes.

Keywords: Body mass index; Diabetes mellitus; Dichlorodiphenyl dichloroethylene; Dieldrin; Hexachlorocyclohexane; Insulin resistance; Prediabetic state

\section{INTRODUCTION}

Persistent organic pollutants (POPs) are characterized by their unique properties such as persistence lipophilicity, toxic effects, bioaccumulation, and long-drawn-out transport in the environment. POPs include organochlorine pesticides (OCPs) group such as aldrin, dieldrin, $\alpha$-endosulfan, $\beta$-endosulfan, hexachlorocyclohexane $(\mathrm{HCH})$ and its isomers, p,p'-dichlorodiphenyl-dichloroethylene (DDE), p,p'-dichloro-diphenyl-trichloroethane (DDT), and p,p'-dichloro-diphenyl-dichloroeth-
Corresponding author: Basu Dev Banerjee (D) https://orcid.org/0000-0002-8348-3989 Environmental Biochemistry and Molecular Biology Laboratory, Department of Biochemistry, University College of Medical Sciences, University of Delhi, Dilshad Garden, Delhi 110095, India

E mail: banerjeebd@hotmail.com
This is an Open Access article distributed under the terms of the Creative Commons Attribution Non-Commercial License (https://creativecommons.org/licenses/by-nc/4.0/) which permits unrestricted non-commercial use, distribution, and reproduction in any medium, provided the original work is properly cited. 
ane (DDD). According to a survey based on the usage of pesticides, $40 \%$ of pesticides used belongs to the organochlorines class [1,2]. In Asia, India is one of the largest producers of general pesticides and ranks 12th worldwide [3].

In India, approximately $70 \%$ of the population lives in rural areas. The rural population is more prone to environmental contamination due to contaminated drinking water, food, and air. Human exposure to OCPs occurs mainly through air, soil, water, flora, fauna, and food chain [4]. The agglomeration of environmental pollutants in human being suggested that it has a significant contribution to the occurrence of the diseases [5].

Diabetes mellitus (DM) is a metabolic disorder caused by insulin resistance, hypertension, hyperglycemia, and limit insulin secretion. Environmental toxicants affect the cofactors responsible for the risk of developing newly detected DM. Environmental toxicants, including organic pollutants, OCPs, heavy metals, and pharmaceutical chemical components increase insulin resistance and also interfere with total cholesterol (TC), triglycerides (TG), and glucose metabolism [6]. OCPs are supposed to be a major factor in increasing type 2 diabetes mellitus (T2DM) [5] and among these only $6 \%$ can be interpreted by genetic and heritable factors which include overweight, genetic, and sex $[7,8]$. Agricultural chemicals are causal factor for environmental contamination [9]. OCPs exposure through occupational or accidental practices were also reported for modified glucose metabolism, increased risk of T2DM, and insulin resistance $[10,11]$. The recent OCPs level in blood samples of newly diagnosed DM and prediabetes represents the current exposure to human beings. As OCPs have a long half-life with assimilation, bioaccumulation, and biomagnification properties, it causes some deleterious effects which may further promote the risk of developing newly detected DM. The present study showed recent OCPs exposure and also correlates the OCPs level with biological parameters. This study also showed the level of OCPs in blood are associated with the risk factors responsible for the conversion of prediabetes to newly detected DM with respect to lipid metabolism, insulin resistance, and glucose intolerance among the North Indian population with reference to the etiology of diabetes.

\section{METHODS}

\section{Study population}

It was a case-control study conducted on 100 normal glucose tolerance (NGT) control, 100 prediabetes, and 100 newly de- tected DM cases in the age group of 30 to 70 years. Age and sex were matched for all study groups. The study was carried out at Environmental Biochemistry and Molecular Biology Laboratory, Department of Biochemistry in collaboration with the Centre for Diabetes, Endocrinology, and Metabolism (DEM), University College of Medical Sciences (UCMS), University of Delhi, and Guru Teg Bahadur (GTB) Hospital, Dilshad Garden, Delhi, India. The study was carried out between February 2016 to February 2019 and the criteria for recruitment of patients were as follows. (1) No history of hypertension, known hypothyroidism, chronic diarrhea, malabsorption, hypothyroidism, Cushing syndrome, and DM. (2) Patients recently diagnosed with prediabetes and diabetes were included in the study. No patient was on medication at the time of the recruitment. (3) All patients (cases and control) were from the same geographic location.

Controls were also selected from the same location, who was visiting GTB Hospital with patients. After fulfilling the inclusion and exclusion criteria subjects were called for a standard oral glucose intolerance test (OGTT) for diagnosis of recently diagnosed prediabetes and newly detected DM groups. No patient was previously exposed or working with any kind of pesticide-related practice. Clinical assessment and anthropometry measurements were performed during OGTT. Education was divided into five grading systems (illiterate, $0-4,5-10,11-12$, and graduate or above). Also, food habit was divided into vegetarian and non-vegetarian. Fat consumption was recorded based on the monthly intake of ghee and other dairy products. Prior written consent was also taken from the patients who were willing to participate in the study. The study was approved by the institutional ethics committee on human research (IECHR) (UCMS/IEC-HR/2015/24/FACULTY/1), UCMS, and GTB Hospital, University of Delhi, Delhi. Written consent form was obtained from all the subjects prior to start the study.

\section{Sample collection and estimation}

Blood samples were collected in the sample collection room of DEM center, UCMS, and GTB Hospital (University of Delhi), Dilshad Garden, Delhi. Blood (3 mL) was withdrawn from the patient after a minimum of 8 hours of overnight fasting $(F)$ for estimation of OGTT, lipid profile, insulin, glycosylated hemoglobin (HbAlc), and OCPs. Plasma glucose levels were estimated on the same day by using glucose oxidase and peroxidase (Randox, Crumlin, UK) [3]. Clinical parameters such as glycosylated hemoglobin (HbAlc), plasma glucose level (F and 
postprandial [PP]), TC, TG, high-density lipoprotein cholesterol (HDL-C), and low-density lipoprotein cholesterol (LDL$\mathrm{C})$, and insulin were also analyzed. Insulin levels were estimated by radioimmune assay (Beckman coulter IM3210; Beckman coulter, Brea, CA, USA). Insulin resistance was calculated using the homeostasis model assessment of insulin resistance (HOMA-IR) and homeostasis model assessment of $\beta$-cell function (HOMA- $\beta$ ). The levels of TC was measured by the cholesterol oxidase-peroxidase (CHOD-POD) method [12], TG estimation was based on Werener and Gabriesulsen (1981) method using the Randox UK kit (enzymatic method). Estimation of HDL-C was done by Autopure HDL-C Accurex biomedicals kits (Accurex, Mumbai, India), and serum LDL-C and very-low-density lipoprotein cholesterol (VLDL-C) were calculated using formula LDL-C $=$ TC-HDL-C $-(\mathrm{TG} / 5)$ and VLDL-C $=\mathrm{TG} / 5$. Furthermore, demographic details like age, body mass index (BMI), and waist were also measured at the time of OGTT. Standardized methods were used for anthropometric measurements, including height, weight, and waist circumference [13]. Height and body weight were measured in very light weighed clothes and without shoes. The BMI was calculated using the formula, weight $(\mathrm{kg}) /$ height $^{2}\left(\mathrm{~m}^{2}\right)$ [14].

\section{Pesticide residue analysis}

The analysis of OCPs residue carried out in blood samples was as follows: isomers of $\mathrm{HCH}(\alpha, \beta$, and $\gamma)$, aldrin, dieldrin, o,p'DDE, p,p'-DDE, and p,p'-DDD. The extraction of OCPs was carried out using (2:1) hexane and acetone of high performance liquid chromatography grade as solvent [15]. Using mixed standard, five samples of blood in triplicate were spiked with 5 and $25 \mathrm{ng} / \mathrm{mL}$, respectively. Analysis of the extract was done with gas chromatography (Perkin Elmer, Waltham, MA, USA) equipped with a ${ }^{63} \mathrm{Ni}$ selective electron capture detector [15]. The column named DB-5 (non-polar, low bleed and has a high temperature) having a length of $60 \mathrm{~m}$ and an internal diameter (ID) of $0.25 \mathrm{~mm}$ was used. The detection limit of the method was $4 \mathrm{pg} / \mathrm{mL}$ for each OCP. The limit of detection of the detector was $0.05 \mathrm{pg}$ perchloroethylene when nitrogen was used as a carrier gas. The average recovery of the samples spiked exceeded $95 \%$. In pesticide analysis, a quality check was always ran two times in a day to maintain its accuracy and reproducibility. The levels of pesticide were expressed as parts per billion (ppb).

\section{Statistical analysis}

Data presentation and statistical analysis were completed using
Microsoft Excel version 2010 (Microsoft, Redmond, WA, USA) and SPSS software version 17.0 (SPSS Inc., Chicago, IL, USA). $P<0.05$ was taken to be significant. Unpaired $t$-test was applied for sociodemographic and clinical data in cases and control for analysis of quantitative and chi-square/Fisher test for qualitative data, respectively. An independent $t$-test was used to calculate difference between two groups and one-way analysis of variance (ANOVA) within three groups with normally distributed data. Mann-Whitney test (for non-Gaussian models) was applied to find significance among three groups for pesticide analysis. Correlations of OCPs with different parameters were analyzed by Spearman's coefficient correlation. To identify significant predictors for OCPs, a multinomial logistic regression model was applied with HbAlc levels as the dependent variable, and the OCPs levels in the blood as the independent variable. Blood OCPs level were adjusted to remove the effect of confounding factors.

\section{RESULTS}

A total of 300 adult patients were enrolled in the study, 100 controls (NGT), 100 prediabetes, and 100 newly detected DM. The sociodemographic characteristics like sex, educational status, occupation, food habit, fat intake, and source of drinking water of study groups are summarized in Table 1.

The literacy level and working status were lower $(P=0.04$ and $P=0.001$, respectively) in the newly detected DM group as compared to the other two groups. Non-vegetarian, high-fat consumption, and under groundwater consumption were significantly high in the newly detected DM group in comparison to prediabetes and controls $(P=0.018, P=0.001$, and $P=0.05$, respectively). Most of the study subjects were residing in urban slums according to the survey and questionnaire. The baseline data of general characteristics like age, BMI, waist, HbAlc, plasma glucose levels ( $\mathrm{F}$ and $\mathrm{PP}$ ), insulin and insulin resistance, TC, TG, HDL-C, and LDL-C were summarized in Table 2.

When the NGT group was compared with the prediabetes group (Group I vs. Group II), BMI, glucose F, and PP was found significantly higher $(P=0.025, P=0.05$, and $P<0.001)$ in the prediabetes group. Waist $(P<0.001)$, BMI $(P<0.001)$, HbAlc $(P<0.001)$, glucose $\mathrm{F}$ and $\mathrm{PP}(P<0.001)$, insulin level $(P<0.001)$, HOMA-IR $(P<0.001)$, TG $(P=0.044)$, and LDL-C $(P=0.025)$ were found highly significant in the newly detected DM group as compared to NGT (Group 1 vs. Group 3). However, when the newly detected DM group was compared with the predia- 
Table 1. Sociodemographic characteristics of control, prediabetes, and newly detected diabetes mellitus subjects

\begin{tabular}{|c|c|c|c|c|}
\hline Parameter & $\begin{array}{l}\text { Control } \\
\text { (Group 1) } \\
(n=100)\end{array}$ & $\begin{array}{c}\text { Prediabetes } \\
\text { (Group 2) } \\
(n=100)\end{array}$ & $\begin{array}{c}\text { Newly } \\
\text { detected DM } \\
(\text { Group 3) } \\
(n=100)\end{array}$ & $P$ value \\
\hline Sex & & & & 0.621 \\
\hline Male & 47 & 56 & 43 & \\
\hline Female & 53 & 44 & 57 & \\
\hline Educational type & & & & $0.040^{\mathrm{a}}$ \\
\hline Illiterate & 41 & 31 & 59 & \\
\hline $0-5$ & 5 & 8 & 11 & \\
\hline $5-10$ & 25 & 26 & 6 & \\
\hline $10-12$ & 29 & 22 & 17 & \\
\hline Graduate or above & 0 & 13 & 7 & \\
\hline Occupation & & & & $0.001^{\mathrm{a}}$ \\
\hline Working & 63 & 57 & 36 & \\
\hline Non-working & 37 & 43 & 64 & \\
\hline Food habit & & & & $0.018^{\mathrm{a}}$ \\
\hline Vegetarian & 47 & 49 & 30 & \\
\hline Non-vegetarian & 53 & 51 & 70 & \\
\hline Fat, /mo & & & & $0.001^{\mathrm{a}}$ \\
\hline $0-200 \mathrm{~g}$ & 28 & 33 & 56 & \\
\hline $200-500 \mathrm{~g}$ & 3 & 5 & 8 & \\
\hline $600-1,500 \mathrm{~g}$ & 25 & 31 & 17 & \\
\hline $1,500 \mathrm{~g}$ and above & 44 & 31 & 19 & \\
\hline $\begin{array}{l}\text { Source of drinking } \\
\text { water }\end{array}$ & & & & $0.041^{\mathrm{a}}$ \\
\hline Tap water & 74 & 64 & 59 & \\
\hline Ground water & 7 & 9 & 14 & \\
\hline Filter water & 19 & 27 & 27 & \\
\hline
\end{tabular}

DM, diabetes mellitus.

${ }^{a} P \leq 0.05$ is significant.

betes group (Group 2 vs. Group 3) waist circumference $(P=$ 0.03), BMI $(P<0.001)$, HbA1c $(P<0.001)$, glucose $\mathrm{F}(P<0.001)$, and PP $(P<0.001)$, insulin level $(P<0.001)$, HOMA-IR $(P<$ $0.001)$, and HOMA- $\beta(P<0.001)$ were found significantly higher in the newly detected DM group (Table 2).

Blood samples were analyzed for OCPs residue namely isomer of $\mathrm{HCH}$, aldrin, dieldrin, p,p'-DDD, o,p'-DDE, and p, p'$\mathrm{DDE}$. The mean \pm standard deviation levels of individual pesticides among the study group were shown in Fig. 1 (Supplementary Table 1$)$. Significantly high levels of $\beta-\mathrm{HCH}(P=$ $0.033, P<0.001)$, aldrin $(P=0.033, P<0.001)$, dieldrin $(P \leq$
$0.001)$, and $\mathrm{p}, \mathrm{p}$-DDE $(P \leq 0.001)$ were found in the prediabetes and newly detected DM group as compared to the control group. Also, a higher levels of $\beta-\mathrm{HCH}(P=0.014)$, aldrin $(P=$ $0.020)$, and dieldrin $(P<0.015)$ were found in the newly detected DM group as compared to the prediabetes group.

In Table 3, BMI was found to be positively correlated with $\alpha-\mathrm{HCH}(P=0.001, r=0.24), \beta-\mathrm{HCH}(P=0.01, r=0.21)$, and aldrin $(P=0.001, r=0.23)$. HbA1c correlated significantly with aldrin $(P=0.05, r=0.15)$, dieldrin $(P \leq 0.001, r=0.27)$ and $\mathrm{p}, \mathrm{p}^{\prime}-$ $\operatorname{DDE}(P=0.006, r=0.20)$. Also $\mathrm{F}$ and $\mathrm{PP}$ glucose were correlated positively with levels of $\beta-\mathrm{HCH}(P=0.01$ and $P \leq 0.001 ; r=$ 0.19 and $r=0.29)$, aldrin $(P=0.05$ and $P=0.007 ; r=0.14$ and $r=$ $0.20)$ and dieldrin $(P<0.001 ; r=0.26$ and $r=0.31)$. However, $\beta$-HCH $(P=0.002, r=0.23)$, dieldrin $(P=0.003, r=0.22)$ showed significant correlation with HOMA-IR. Insulin levels showed significant correlation with $\beta-\mathrm{HCH}(P \leq 0.001, r=$ $0.26)$ and dieldrin $(P=0.008, r=0.19)$. Moreover, $\mathrm{p}, \mathrm{p}^{\prime}$-DDE was significantly positively correlated only with PP glucose levels $(P<0.001, r=0.26)$. Although, HDL-C levels were negatively correlated with $\beta$ - $\mathrm{HCH}(P=0.03, r=-0.16)$, dieldrin $(P=0.04$, $r=-0.15)$. This showed that $\beta-\mathrm{HCH}$, dieldrin and $\mathrm{p}, \mathrm{p}^{\prime}-\mathrm{DDE}$ were significantly correlated with $\mathrm{BMI}, \mathrm{HbA} 1 \mathrm{c}, \mathrm{F}$ and $\mathrm{PP}$, insulin, and HOMA-IR.

When we analyze the correlation of OCPs with itself and one another, we have found that $\beta-\mathrm{HCH}$ was significantly correlated with $\gamma$-HCH, aldrin, and p,p'-DDE (Supplementary Table 2 ). Also, aldrin and dieldrin showed a strong correlation with each other. While, p,p'-DDE showed a significant correlation with $\beta-\mathrm{HCH}$, aldrin, dieldrin, and o,p'-DDE.

In context to this, we analyzed the association of fat intake, food habit, fat intake and sources of drinking water with OCPs (Supplementary Figs. 1-3), we have found that non-vegetarians have a strong association with $\beta-\mathrm{HCH}$, dieldrin, o,p'-DDE, and p,p'-DDE. However, a strong association of OCPs with highfat intake subjects were found in the study group. So we can say that fat might be responsible for the storage and accumulation of OCPs in the human body among North Indians. Further, a significant strong association of OCPs with groundwater samples were also found in the study.

When we analyzed risk with multiple logistic regression model, we found that in the unadjusted model (Model 1) blood levels of $\beta$-HCH (odds ratio [OR], 2.63; 95\% confidence interval [CI], 1.35 to 5.12), dieldrin (OR, 2.83; 95\% CI, 1.46 to 5.49), and p,p'-DDE (OR, 2.49; 95\% CI, 1.28 to 4.85) were found to increase the risk of insulin resistance and glucose in- 
Table 2. Comparison of clinical and anthropometric parameters of control, prediabetes, and newly detected DM subjects

\begin{tabular}{|c|c|c|c|c|}
\hline Parameter & $\begin{array}{c}\text { Control } \\
\text { (Group 1) }(n=100)\end{array}$ & $\begin{array}{c}\text { Prediabetes } \\
(\text { Group 2) }(n=100)\end{array}$ & $\begin{array}{l}\text { Newly detected DM } \\
\text { (Group 3) }(n=100)\end{array}$ & $P$ value \\
\hline \multirow[t]{3}{*}{ Age, yr } & $43.90 \pm 6.79$ & $44.50 \pm 6.47$ & $43.78 \pm 7.67$ & 1 vs. $2=0.639$ \\
\hline & & & & 1 vs. $3=0.927$ \\
\hline & & & & 2 vs. $3=0.575$ \\
\hline \multirow[t]{3}{*}{ BMI, kg/m² } & $28.23 \pm 6.02$ & $31.05 \pm 5.72$ & $34.1 \pm 0.72$ & 1 vs. $2=0.025^{\mathrm{a}}$ \\
\hline & & & & 1 vs. $3<0.001^{\mathrm{a}}$ \\
\hline & & & & 2 vs. $3<0.001^{\text {a }}$ \\
\hline \multirow[t]{3}{*}{ Waist, cm } & $92.85 \pm 16.38$ & $95.78 \pm 15.51$ & $101.70 \pm 12.42$ & 1 vs. $2=0.281$ \\
\hline & & & & 1 vs. $3=0.001^{\mathrm{a}}$ \\
\hline & & & & 2 vs. $3=0.030^{\mathrm{a}}$ \\
\hline \multirow[t]{3}{*}{ Systolic blood pressure, $\mathrm{mm} \mathrm{Hg}$} & $127.42 \pm 9.63$ & $127.92 \pm 8.59$ & $129.51 \pm 10.13$ & 1 vs. $2=0.675$ \\
\hline & & & & 1 vs. $3=0.088$ \\
\hline & & & & 2 vs. $3=0.425$ \\
\hline \multirow[t]{3}{*}{ Diastolic blood pressure, $\mathrm{mm} \mathrm{Hg}$} & $77.09 \pm 11$ & $78.58 \pm 10.58$ & $78.92 \pm 11$ & 1 vs. $2=0.589$ \\
\hline & & & & 1 vs. $3=0.678$ \\
\hline & & & & 2 vs. $3=0.485$ \\
\hline \multirow[t]{3}{*}{$\mathrm{HbA1c}, \%$} & $5.24 \pm 0.31$ & $5.51 \pm 0.52$ & $7.14 \pm 1.75$ & 1 vs. $2=0.171$ \\
\hline & & & & 1 vs. $3<0.001^{a}$ \\
\hline & & & & 2 vs. $3<0.001^{\text {a }}$ \\
\hline \multirow[t]{3}{*}{ Glucose fasting, $\mathrm{mg} / \mathrm{dL}$} & $86.52 \pm 6.59$ & $97.68 \pm 11.38$ & $138.30 \pm 53.53$ & 1 vs. $2=0.05^{\mathrm{a}}$ \\
\hline & & & & 1 vs. $3<0.001^{\mathrm{a}}$ \\
\hline & & & & 2 vs. $3<0.001^{\text {a }}$ \\
\hline \multirow[t]{3}{*}{ Glucose PP, mg/dL } & $107.90 \pm 17.79$ & $154.58 \pm 22.39$ & $285.25 \pm 93.85$ & 1 vs. $2<0.001^{\mathrm{a}}$ \\
\hline & & & & 1 vs. $3<0.001^{\mathrm{a}}$ \\
\hline & & & & 2 vs. $3<0.001^{a}$ \\
\hline \multirow[t]{3}{*}{ Insulin, $\mathrm{mIU} / \mathrm{L}$} & $11.44 \pm 5.77$ & $14.52 \pm 11.47$ & $30.38 \pm 10.60$ & 1 vs. $2=0.081$ \\
\hline & & & & 1 vs. $3<0.001^{\mathrm{a}}$ \\
\hline & & & & 2 vs. $3<0.001^{\text {a }}$ \\
\hline \multirow[t]{3}{*}{ HOMA-IR } & $2.45 \pm 1.27$ & $3.52 \pm 2.85$ & $11.06 \pm 7.59$ & 1 vs. $2=0.220$ \\
\hline & & & & 1 vs. $3<0.001^{\mathrm{a}}$ \\
\hline & & & & 2 vs. $3<0.001^{\text {a }}$ \\
\hline \multirow[t]{3}{*}{$\mathrm{TC}, \mathrm{mg} / \mathrm{dL}$} & $183.31 \pm 67.19$ & $192.67 \pm 47.63$ & $194.48 \pm 44.36$ & 1 vs. $2=0.344$ \\
\hline & & & & 1 vs. $3=0.259$ \\
\hline & & & & 2 vs. $3=0.854$ \\
\hline \multirow[t]{3}{*}{$\mathrm{TG}, \mathrm{mg} / \mathrm{dL}$} & $141.02 \pm 66.09$ & $152.33 \pm 69.53$ & $166.96 \pm 74.49$ & 1 vs. $2=0.378$ \\
\hline & & & & 1 vs. $3=0.044^{\mathrm{a}}$ \\
\hline & & & & 2 vs. $3=0.255$ \\
\hline \multirow[t]{3}{*}{$\mathrm{HDL}-\mathrm{C}, \mathrm{mg} / \mathrm{dL}$} & $44.85 \pm 10.52$ & $43.92 \pm 13.16$ & $42.53 \pm 9.06$ & 1 vs. $2=0.644$ \\
\hline & & & & 1 vs. $3=0.252$ \\
\hline & & & & 2 vs. $3=0.494$ \\
\hline \multirow[t]{3}{*}{ LDL-C, mg/dL } & $112.03 \pm 48.05$ & $114.04 \pm 49.38$ & $127.98 \pm 69.75$ & 1 vs. $2=0.337$ \\
\hline & & & & 1 vs. $3=0.025^{\mathrm{a}}$ \\
\hline & & & & 2 vs. $3=0.196$ \\
\hline
\end{tabular}

Values are presented as mean \pm standard deviation.

DM, diabetes mellitus; BMI, body mass index; HbA1c, glycosylated hemoglobin; PP, postprandial; HOMA-IR, homeostasis model assessment of insulin resistance; TC, total cholesterol; TG, total triglycerides; HDL-C, high-density lipoprotein cholesterol; LDL-C, low-density lipoprotein cholesterol.

${ }^{\mathrm{a}} P \leq 0.05$ was significant. 


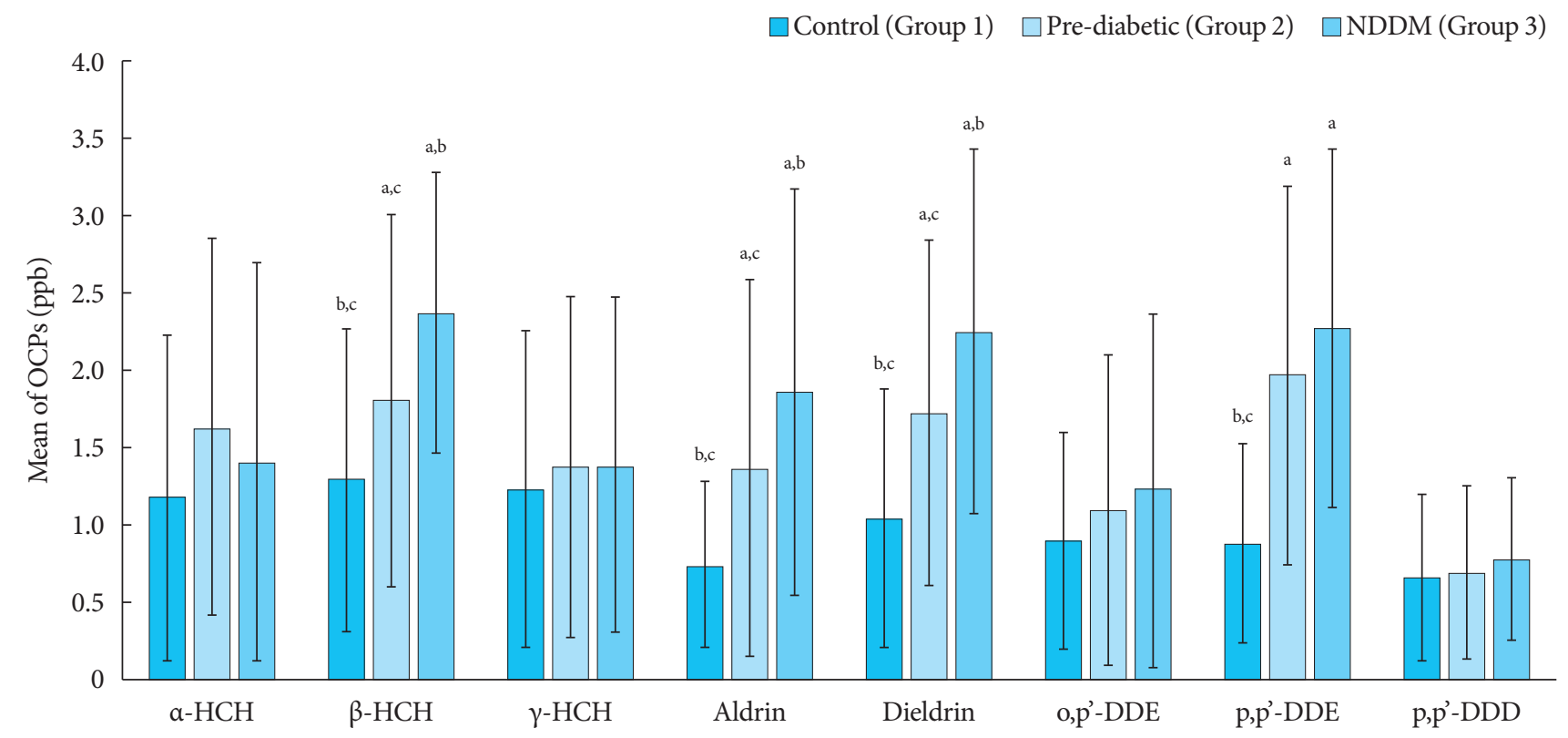

Fig. 1. Organochlorine pesticides (OCPs) level in blood samples of control, prediabetic, and newly detected diabetes mellitus (DM) group. The values of OCPs are expressed in mean; error bar denotes \pm standard deviation; all differences were significant at $P<0.05$ levels. ppb, parts per billion; HCH, hexachlorocyclohexane; DDE, dichloro-diphenyl-dichloroethylene; DDD, dichlorodiphenyl-dichloroethane. aThese denote significant with regards to controls, ${ }^{b} T h e s e$ denote significant with regards to prediabetic, 'These denote significant with regards newly detected DM.

Table 3. Correlation of blood organochlorine pesticides level with biochemical parameters in the study group

\begin{tabular}{|c|c|c|c|c|c|c|c|c|c|c|c|}
\hline Parameter & Correlation & BMI & Waist & $\mathrm{Hb} 1 \mathrm{Ac}$ & Fasting & $\mathrm{PP}$ & TC & TG & HDL-C & Insulin & HOMA-IR \\
\hline \multirow[t]{2}{*}{ a-HCH } & $P$ value & 0.001 & 0.39 & 0.48 & 0.84 & 0.79 & 0.73 & 0.77 & 0.30 & 0.97 & 0.90 \\
\hline & $r$ & $0.24^{\mathrm{a}}$ & -0.06 & 0.05 & 0.01 & 0.02 & 0.02 & 0.02 & -0.07 & -0.003 & -0.009 \\
\hline \multirow[t]{2}{*}{$\beta-\mathrm{HCH}$} & $P$ value & 0.005 & 0.66 & 0.22 & 0.01 & 0.00 & 0.83 & 0.50 & 0.03 & 0.00 & 0.002 \\
\hline & $r$ & $0.21^{\mathrm{a}}$ & 0.03 & 0.09 & $0.19^{\mathrm{b}}$ & $0.29^{\mathrm{a}}$ & -0.02 & -0.05 & $-0.16^{\mathrm{b}}$ & $0.26^{\mathrm{a}}$ & $0.23^{\mathrm{a}}$ \\
\hline \multirow[t]{2}{*}{$\gamma-\mathrm{HCH}$} & $P$ value & 0.12 & 0.49 & 0.76 & 0.64 & 0.93 & 0.78 & 0.43 & 0.22 & 0.49 & 0.54 \\
\hline & $r$ & 0.11 & -0.05 & -0.02 & 0.03 & $0.006^{\mathrm{b}}$ & 0.021 & -0.05 & -0.09 & $0.05^{\mathrm{b}}$ & $0.05^{\mathrm{b}}$ \\
\hline \multirow[t]{2}{*}{ Aldrin } & $P$ value & 0.001 & 0.16 & 0.05 & 0.05 & 0.007 & 0.73 & 0.45 & 0.89 & 0.05 & 0.08 \\
\hline & $r$ & $0.23^{\mathrm{a}}$ & 0.10 & $0.15^{\mathrm{b}}$ & 0.14 & $0.20^{\mathrm{a}}$ & -0.02 & 0.06 & -0.01 & 0.14 & 0.13 \\
\hline \multirow[t]{2}{*}{ Dieldrin } & $P$ value & 0.88 & 0.82 & 0.00 & 0.00 & 0.00 & 0.89 & 0.85 & 0.04 & 0.008 & 0.003 \\
\hline & $r$ & 0.01 & 0.02 & $0.27^{\mathrm{a}}$ & $0.26^{\mathrm{a}}$ & $0.31^{\mathrm{a}}$ & -0.01 & -0.01 & $-0.15^{\mathrm{b}}$ & $0.19^{\mathrm{a}}$ & $0.22^{\mathrm{a}}$ \\
\hline \multirow[t]{2}{*}{ o,p'-DDE } & $P$ value & 0.31 & 0.84 & 0.56 & 0.85 & 0.63 & 0.55 & 0.30 & 0.33 & 0.04 & 0.34 \\
\hline & $r$ & -0.08 & 0.01 & 0.04 & 0.01 & 0.04 & -0.04 & 0.07 & -0.07 & $0.15^{\mathrm{b}}$ & 0.07 \\
\hline \multirow[t]{2}{*}{$\mathrm{p}, \mathrm{p}$-DDE } & $P$ value & 0.96 & 0.47 & 0.006 & 0.22 & 0.00 & 0.77 & 0.48 & 0.56 & 0.11 & 0.44 \\
\hline & $r$ & 0.004 & 0.05 & $0.20^{\mathrm{a}}$ & 0.09 & $0.26^{\mathrm{a}}$ & 0.02 & 0.05 & 0.04 & 0.12 & 0.06 \\
\hline \multirow[t]{2}{*}{ p,p'-DDD } & $P$ value & 0.43 & 0.96 & 0.44 & 0.84 & 0.49 & 0.46 & 0.37 & 0.37 & 0.73 & 0.93 \\
\hline & $r$ & 0.06 & 0.004 & -0.06 & 0.01 & 0.05 & -0.05 & -0.07 & -0.07 & -0.03 & -0.007 \\
\hline
\end{tabular}

BMI, body mass index; HbA1c, glycosylated hemoglobin; PP, postprandial; TC, total cholesterol; TG, total triglycerides; HDL-C, high-density lipoprotein cholesterol; HOMA-IR, homeostasis model assessment of insulin resistance; HCH, hexachlorocyclohexane; DDE, dichloro-diphenyl-dichloroethylene; DDD, dichloro-diphenyl-dichloroethane.

${ }^{\mathrm{a}} \mathrm{P} \leq 0.01,{ }^{\mathrm{b}} \mathrm{P} \leq 0.05$. 
Table 4. Multiple logistic regression models for the concentration of OCPs and risk of diabetes

\begin{tabular}{|c|c|c|c|c|c|c|c|c|}
\hline \multirow{2}{*}{ Parameter } & \multicolumn{2}{|c|}{ Model 1} & \multicolumn{2}{|c|}{ Model 2} & \multicolumn{2}{|c|}{ Model 3} & \multicolumn{2}{|c|}{ Model 4} \\
\hline & OR $(95 \% \mathrm{CI})$ & $P$ value & OR (95\% CI) & $P$ value & OR $(95 \% \mathrm{CI})$ & $P$ value & OR $(95 \% \mathrm{CI})$ & $P$ value \\
\hline$\alpha-\mathrm{HCH}$ & $1.19(0.64-2.19)$ & 0.579 & $1.17(0.63-2.19)$ & 0.685 & $1.12(0.60-2.08)$ & 0.719 & $1.31(0.67-2.52)$ & 0.427 \\
\hline$\beta-\mathrm{HCH}$ & $2.63(1.35-5.12)$ & $0.004^{\mathrm{a}}$ & $2.70(1.38-5.29)$ & $0.004^{\mathrm{a}}$ & $2.88(1.45-5.71)$ & $0.002^{\mathrm{a}}$ & $2.40(1.18-4.87)$ & $0.015^{\mathrm{b}}$ \\
\hline$\gamma-\mathrm{HCH}$ & $1.14(0.62-2.12)$ & 0.674 & $1.22(0.64-2.32)$ & 0.545 & $1.08(0.58-2.02)$ & 0.806 & $0.92(0.48-1.75)$ & 0.398 \\
\hline Aldrin & $1.45(0.76-2.76)$ & 0.263 & $1.60(0.81-3.17)$ & 0.176 & $1.49(0.77-2.86)$ & 0.232 & $0.97(0.50-1.88)$ & 0.934 \\
\hline Dieldrin & $2.83(1.46-5.49)$ & $0.002^{\mathrm{a}}$ & $2.83(1.46-5.52)$ & $0.002^{\mathrm{a}}$ & $2.71(1.39-5.31)$ & $0.004^{\mathrm{a}}$ & $2.18(1.10-4.33)$ & $0.025^{\mathrm{b}}$ \\
\hline o,p'-DDE & $1.23(0.67-2.27)$ & 0.506 & $1.23(0.66-2.27)$ & 0.520 & $1.31(0.70-2.43)$ & 0.398 & $1.16(0.61-2.23)$ & 0.643 \\
\hline $\mathrm{p}, \mathrm{p}^{\prime}-\mathrm{DDE}$ & $2.49(1.28-4.85)$ & $0.007^{\mathrm{a}}$ & $2.55(1.29-5.02)$ & $0.007^{\mathrm{a}}$ & $2.63(1.33-5.19)$ & $0.005^{\mathrm{a}}$ & $1.76(0.89-3.51)$ & $0.050^{\mathrm{b}}$ \\
\hline p,p'DDD & $0.77(0.42-1.42)$ & 0.398 & $0.81(0.43-1.51)$ & 0.506 & $0.81(0.43-1.49)$ & 0.494 & $1.14(0.59-2.19)$ & 0.698 \\
\hline
\end{tabular}

Model 1: crude ratio; Model 2: adjusted for age and body mass index; Model 3: adjusted for triglycerides and cholesterol; Model 4: adjusted for demographic data.

$\mathrm{OR}$, odds ratio; $\mathrm{CI}$, confidence interval; $\mathrm{HCH}$, hexachlorocyclohexane; DDE, dichloro-diphenyl-dichloroethylene; DDD, dichloro-diphenyl-dichloroethane.

${ }^{\mathrm{a}} P \leq 0.01,{ }^{\mathrm{b}} P \leq 0.05$.

Table 5. Multiple logistic regression models for the concentration of OCPs and risk of diabetes based on the BMI categories

\begin{tabular}{|c|c|c|c|c|c|c|}
\hline \multirow{2}{*}{ Parameter } & \multicolumn{2}{|c|}{$\mathrm{BMI}<23 \mathrm{~kg} / \mathrm{m}^{2}$} & \multicolumn{2}{|c|}{$\mathrm{BMI} \geq 23$ and $\leq 25 \mathrm{~kg} / \mathrm{m}^{2}$} & \multicolumn{2}{|c|}{$\mathrm{BMI}>25 \mathrm{~kg} / \mathrm{m}^{2}$} \\
\hline & OR $(95 \% \mathrm{CI})$ & $P$ value & OR $(95 \%$ CI $)$ & $P$ value & OR $(95 \% \mathrm{CI})$ & $P$ value \\
\hline a-HCH & $0.60(0.09-3.98)$ & 0.597 & $1.78(0.87-3.64)$ & 0.109 & $0.36(0.06-2.15)$ & 0.262 \\
\hline$\beta-\mathrm{HCH}$ & $1.80(0.85-3.80)$ & $0.012^{\mathrm{a}}$ & $4.00(0.50-24.98)$ & 0.191 & $10.05(1.36-43.05)$ & $0.024^{\mathrm{a}}$ \\
\hline$\gamma-\mathrm{HCH}$ & $1.50(0.23-9.79)$ & 0.672 & $0.97(0.48-1.97)$ & 0.947 & $0.52(0.067-4.0)$ & 0.529 \\
\hline Aldrin & $1.50(0.37-12.8)$ & 0.347 & $0.80(0.38-1.66)$ & 0.550 & $0.40(0.03-5.25)$ & 0.485 \\
\hline Dieldrin & $1.40(0.19-2.43)$ & 0.738 & $1.95(0.95-3.98)$ & $0.046^{\mathrm{a}}$ & $7.00(0.97-30.57)$ & $0.050^{\mathrm{a}}$ \\
\hline o,p'-DDE & $0.90(0.13-6.08)$ & 0.914 & $1.50(0.74-6.05)$ & 0.262 & $0.375(0.61-4.30)$ & 0.290 \\
\hline $\mathrm{p}, \mathrm{p}^{\prime}-\mathrm{DDE}$ & $1.33(0.14-7.37)$ & 0.800 & $1.29(0.59-8.82)$ & $0.050^{\mathrm{a}}$ & $10.66(1.38-36.03)$ & $0.013^{\mathrm{a}}$ \\
\hline p,p'-DDD & $2.40(0.29-10.78)$ & 0.416 & $1.21(0.59-3.45)$ & 0.601 & $1.78(0.28-11.1)$ & 0.538 \\
\hline
\end{tabular}

Model crude ratio.

BMI, body mass index; OR, odds ratio; CI, confidence interval; $\mathrm{HCH}$, hexachlorocyclohexane; DDE, dichloro-diphenyl-dichloroethylene; DDD, dichloro-diphenyl-dichloroethane.

${ }^{\mathrm{a}} \mathrm{P} \leq 0.05$.

tolerance by $2.63,2.83$, and 2.49 times respectively (Table 4 ). Also, when OCPs data was adjusted for age and BMI (Model 2) again $\beta$ - $\mathrm{HCH}$ (OR, 2.70; 95\% CI, 1.38 to 5.29 ), dieldrin (OR, 2.83; $95 \% \mathrm{CI}, 1.46$ to 5.52 ), and p,p'-DDE (OR, 2.55; 95\% CI, 1.29 to 5.02 ) blood levels were found to increase the risk of insulin resistance and glucose intolerance by $2.70,2.83$, and 2.55 times respectively. Moreover, after adjusting OCPs for TG and TC (Model 3), $\beta$-HCH (OR, 2.88; 95\% CI, 1.45 to 5.71), dieldrin (OR, 2.71; 95\% CI, 1.39 to 5.31), and p,p'-DDE (OR, 2.63; $95 \%$ CI, 1.33 to 5.19 ) blood levels were found to increase the risk factors for newly detected DM by $2.88,2.71$, and 2.63 times respectively. Likewise, when adjusted for demographic parameters like food habit, fat, and drinking water (Model 4), $\beta-\mathrm{HCH}$ (OR, 2.40; 95\% CI, 1.18 to 4.87), dieldrin (OR, 2.18; 95\% CI, 1.10 to 4.33 ), and p,p'-DDE (OR, 1.76 ; $95 \%$ CI, 0.89 to 3.51) blood levels were found to increase the risk factor of newly detected DM by $2.40,2.18$, and 1.76 times, respectively (Table 4).

When we adjusted the OCPs data for BMI categories, we have found that risk is strongly associated with subjects having higher BMI, i.e., BMI $\geq 23$ and $\leq 25$ and $>25 \mathrm{~kg} / \mathrm{m}^{2}$ (Table 5). When OCPs data was adjusted for BMI $\geq 23$ and $\leq 25 \mathrm{~kg} / \mathrm{m}^{2}$, $\beta$-HCH (OR, 1.80; $P=0.012)$, dieldrin ( $\mathrm{OR}, 1.95 ; P=0.046$ ), and $\mathrm{p}, \mathrm{p}$-DDE (OR, 1.29; $P=0.050)$ blood levels were found to 
increase the risk of developing newly detected DM by 1.80 , 1.95, and 1.29 times, respectively. Also, when we adjusted for BMI $>25 \mathrm{~kg} / \mathrm{m}^{2}$, we have found the risk of developing newly detected DM by $10.05,7$, and 10.66 times, respectively. This further confirms that $\beta-\mathrm{HCH}$, dieldrin and p,p'-DDE increase the risk of developing newly detected DM.

\section{DISCUSSION}

The present study showed the recent trend of OCPs in human blood sample and also identified its associated risk of developing newly detected DM (which is the primary stage of diabetes) with altered glucose intolerance, lipid dysfunction, and insulin resistance in the North Indian population. This study also showed that OCPs level in blood was strongly correlated with insulin resistance with varying degrees of glucose intolerance, even after adjustment for confounding factors like; BMI ( $\geq 23$ and $\leq 25$ and $>25 \mathrm{~kg} / \mathrm{m}^{2}$ ), TC, age, and serum TG. This study also observed the level of pesticide responsible for developing prediabetes and its further expansion to newly detected DM. Human beings are exposed to OCPs through air and water contaminated with industrial waste as well as through agricultural goods and consumer products [16]. However, continuous use of OCPs without proper safety measures also causes accumulation of OCPs residue in the human body [17]. Various epidemiological studies also showed the positive association of OCPs with T2DM $[18,19]$.

To investigate, we have analyzed 300 blood samples divided into three groups as cases (prediabetes and newly detected $\mathrm{DM}$ ) and control (NGT). In the present study, we have found significantly high levels of $\beta-\mathrm{HCH}$ in prediabetes and newly detected DM group when compared to controls. This is in line with earlier studies reported high OCPs level in T2DM as compared to the control group [20-23]. A higher level of $\beta-\mathrm{HCH}$ represents a current exposure that is either through polluted air, food, drinking water. Although, a public health program has completely banned the usage of these pesticides in India since April $1997 \mathrm{HCH}$ is still in use in developing countries like India and China, and it is likely to affect health chronically. As $\mathrm{HCH}$ is the most stubborn OCP and get cleared from the body very slowly as compared to other isomers, it is easily detected in human blood.

In the present study, we have also found that the level of dieldrin in prediabetes and newly detected DM groups were higher in comparison to the control group and showed a significant association with $\mathrm{HbAlc}$, glucose tolerance and insulin resistance. The findings of this study were in support of a previously reported study by Post et al. [24], 2010 that increased level of $\mathrm{HbA1c}$ in the blood was significantly correlated with the high level of dieldrin in the human body [24,25]. Various rigorous agricultural activities cause leakage and seepage of OCPs (aldrin, $\mathrm{HCH}, \mathrm{DDT}$, and its metabolites, etc.) into water bodies and soil which may enter into the human body and may damage the normal functioning of the body [26]. Further, the continuous increase of environmental pollutants in the human body may lead to the disruption of the normal functioning of the body and may result in the occurrence of various kind of diseases [5]. The type of pesticide, duration and route of exposure, and the individual health status (e.g., age, BMI, fat, drinking water, nutritional deficiencies, and healthy/damaged skin) are determining factors for the level of pesticides in the body.

In the study, levels of $\mathrm{p}, \mathrm{p}^{\prime}-\mathrm{DDE}$ in the blood of prediabetes and newly detected DM group was also higher as compared to the control group (Fig. 1). This observation has been supported by an earlier report by Son et al. [27]. The occurrence of metabolites of DDT in serum showed the presence of DDT in the environment. Although, DDT was banned by various countries but still it is in use for various vector control programs. The half-life of p,p'-DDT and its metabolites have been assumed to be 6 to 7 years [28]. DDT has a long half-life with bioaccumulation and magnification properties and also persistent so it can still be detected in the environment [29]. OCPs and their other metabolites were assumed to impart a higher risk of increasing T2DM and other associated problems [30]. So, monitoring blood OCPs level from time to time is necessary to maintain human health and to minimize the problems associated with it.

As indicated by this study, higher levels of OCPs in blood disturb the glucose plasma levels, insulin resistance and disrupt $\beta$-cells which increases the risk of developing diabetes. We have found a strong positive correlation of $\beta-\mathrm{HCH}$, dieldrin, and p,p'-DDE with glucose F and PP, insulin, and HOMA-IR in the blood which showed that these may be somehow associated with each other (Table 3). In demographic data, we have found that non-vegetarians, fat intake, and groundwater were positively and significantly associated with the increased level of OCPs in human blood. As obesity is a major risk factor for T2DM and excess fat consumption is directly related to obesity development. DDT tends to get stored in body fat and it was also showed by correlation and regression in this study. Fat and 
age have a strong protective effect on storing OCP in the human body. Various studies confirmed that p,p'-DDE was the most expected residue among all the pesticides found in highfat products. In comparison to the southern part of India, North India has a high consumption of ghee and dairy products [31,32]. In the present study, we have also found that food habits and fat have a significant association with blood OCPs level (Supplementary Figs. 1 and 2). This observation has been supported by and Tuomi et al. [33] in 2005 and Sladek et al. [34] in 2007. Higher OCPs level in the blood of prediabetes and diabetes group and its strong correlation with F, PP, lipid, insulin, and HOMA-IR again confirms that continuous exposure of OCPs via environmental exposure (i.e., food, fat intake, drinking water, and air) may tend to increase the OCPs load in the human body which may increase the risk of developing diabetes by disturbing various biological functions within the body. So, the government needs to implement some very strong regulations on the illegal use of DDT and $\mathrm{HCH}$.

Further, the result of multivariate logistic regression analysis in this study confirmed that $\beta-\mathrm{HCH}$, dieldrin, and $\mathrm{p}, \mathrm{p}$-DDE levels in the prediabetes and newly detected DM group were of dominant influence on human health especially with people of higher age, BMI $\left(>25 \mathrm{~kg} / \mathrm{m}^{2}\right)$, fat, and lipid. Changes in lipid level and glucose metabolism were strongly interrelated with the OCPs exposure [35-37]. Disruption during the main phase of development can lead to susceptible changes in tissue, expression of a gene or other genetic composition that may lead to long-term or permanent dysfunction. This may result in increased vulnerability to chronic diseases such as obesity, metabolic syndrome, diabetes, cardiovascular diseases, and varying types of cancer [38]. This study also concludes that OCPs may play a major role in the disruption of the biological functioning of the body which in turn associated with the development of T2DM risk in the North Indian population. This study gives a recent trend of OCP in human blood and its outcomes on biochemical parameters which are one of the important aspects for maintaining public health. This study also has a few limitations. First, because of the small sample size, stratified analysis was not possible and maybe some associations were chance findings. Second, confirmation of the cause-result relationship with this study is not possible.

In conclusion, the study concludes that high OCPs level in the blood may lead to glucose intolerance and insulin resistance which may cause the risk of developing T2DM. Also, high OCPs level in the body of patients with higher BMI indi- cate that patients with higher BMI have higher risk of developing T2DM after a certain period. This study also showed the level of OCPs in blood are associated with the risk factors responsible for the conversion of prediabetes to newly detected DM such as lipid metabolism, insulin resistance, and glucose intolerance among North Indian population. OCPs level present in the environment may be considered as one of the major factors for metabolic and endocrine disruptions and might play a crucial role in the etiology of diabetes. Future studies should encourage the estimation of OCPs through the route of exposure such as ingestion, inhalation and dermal contact and its correlation in blood levels, lipid, HbAlc, and glucose homeostasis to better understand the mechanism behind these endocrine changes.

\section{SUPPLEMENTARY MATERIALS}

Supplementary materials related to this article can be found online at https://doi.org/10.4093/dmj.2020.0093.

\section{CONFLICTS OF INTEREST}

No potential conflict of interest relevant to this article was reported.

\section{AUTHOR CONTRIBUTIONS}

Conception or design: A.J.U., B.D.B., S.V.M.

Acquisition, analysis, or interpretation of data: S.T., B.K.M., T.S., N.T., B.D.B., S.V.M.

Drafting the work or revising: S.T., B.K.M., T.S., N.T., B.D.B., S.V.M.

Final approval of the manuscript: S.T., A.J.U., B.D.B., S.V.M.

\section{ORCID}

Shipra Tyagi https://orcid.org/0000-0002-0004-8771

Basu Dev Banerjee https://orcid.org/0000-0002-8348-3989

\section{FUNDING}

The University of Delhi provided the purse research grant, 2016 under funding of Department of Science and Technology (DST) to one of the senior authors (Abdul Jamil Urfi). 


\section{ACKNOWLEDGMENTS}

One of the authors, Shipra Tyagi was recipient of the Inspire Senior Research Fellowship (SRF) (IF160105).

\section{REFERENCES}

1. Bondad-Reantaso MG, Subasinghe RP, Arthur JR, Ogawa K, Chinabut S, Adlard R, et al. Disease and health management in Asian aquaculture. Vet Parasitol 2005;132:249-72.

2. Gupta PK. Pesticide exposure: Indian scene. Toxicology 2004; 198:83-90.

3. Barham D, Trinder P. An improved colour reagent for the determination of blood glucose by the oxidase system. Analyst 1972;97:142-5.

4. Anderson SE, Meade BJ. Potential health effects associated with dermal exposure to occupational chemicals. Environ Health Insights 2014;8:51-62.

5. Patel CJ, Bhattacharya J, Butte AJ. An environment-wide association study (EWAS) on type 2 diabetes mellitus. PLoS One 2010;5:e10746.

6. Jones OA, Maguire ML, Griffin JL. Environmental pollution and diabetes: a neglected association. Lancet 2008;371:287-8.

7. Baliunas DO, Taylor BJ, Irving H, Roerecke M, Patra J, Mohapatra S, et al. Alcohol as a risk factor for type 2 diabetes: a systematic review and meta-analysis. Diabetes Care 2009;32: 2123-32.

8. Eichler EE, Flint J, Gibson G, Kong A, Leal SM, Moore JH, et al. Missing heritability and strategies for finding the underlying causes of complex disease. Nat Rev Genet 2010;11:446-50.

9. Kuo CC, Moon K, Thayer KA, Navas-Acien A. Environmental chemicals and type 2 diabetes: an updated systematic review of the epidemiologic evidence. Curr Diab Rep 2013;13:831-49.

10. Bertazzi PA, Bernucci I, Brambilla G, Consonni D, Pesatori AC. The Seveso studies on early and long-term effects of dioxin exposure: a review. Environ Health Perspect 1998;106 Suppl 2:625-33

11. Longnecker MP, Michalek JE. Serum dioxin level in relation to diabetes mellitus among Air Force veterans with background levels of exposure. Epidemiology 2000;11:44-8.

12. Allain CC, Poon LS, Chan CS, Richmond W, Fu PC. Enzymatic determination of total serum cholesterol. Clin Chem 1974;20: 470-5.

13. Misra A, Vikram NK, Gupta R, Pandey RM, Wasir JS, Gupta VP. Waist circumference cutoff points and action levels for
Asian Indians for identification of abdominal obesity. Int J Obes (Lond) 2006;30:106-11.

14. Snehalatha C, Viswanathan V, Ramachandran A. Cutoff values for normal anthropometric variables in Asian Indian adults. Diabetes Care 2003;26:1380-4.

15. Mustafa M, Pathak R, Tripathi AK, Ahmed RS, Guleria K, Banerjee BD. Maternal and cord blood levels of aldrin and dieldrin in Delhi population. Environ Monit Assess 2010;171:6338.

16. Li QQ, Loganath A, Chong YS, Tan J, Obbard JP. Persistent organic pollutants and adverse health effects in humans. J Toxicol Environ Health A 2006;69:1987-2005.

17. Abhilash PC, Singh N. Pesticide use and application: an Indian scenario. J Hazard Mater 2009;165:1-12.

18. Everett CJ, Frithsen IL, Diaz VA, Koopman RJ, Simpson WM Jr, Mainous AG 3rd. Association of a polychlorinated dibenzop-dioxin, a polychlorinated biphenyl, and DDT with diabetes in the 1999-2002 National Health and Nutrition Examination Survey. Environ Res 2007;103:413-8.

19. Turyk M, Anderson H, Knobeloch L, Imm P, Persky V. Organochlorine exposure and incidence of diabetes in a cohort of Great Lakes sport fish consumers. Environ Health Perspect 2009;117:1076-82.

20. Everett CJ, Matheson EM. Biomarkers of pesticide exposure and diabetes in the 1999-2004 national health and nutrition examination survey. Environ Int 2010;36:398-401.

21. Arrebola JP, Pumarega J, Gasull M, Fernandez MF, Martin-Olmedo P, Molina-Molina JM, et al. Adipose tissue concentrations of persistent organic pollutants and prevalence of type 2 diabetes in adults from Southern Spain. Environ Res 2013;122: 31-7.

22. Al-Othman AA, Abd-Alrahman SH, Al-Daghri NM. DDT and its metabolites are linked to increased risk of type 2 diabetes among Saudi adults: a cross-sectional study. Environ Sci Pollut Res Int 2015;22:379-86.

23. Cox S, Niskar AS, Narayan KM, Marcus M. Prevalence of selfreported diabetes and exposure to organochlorine pesticides among Mexican Americans: Hispanic health and nutrition examination survey, 1982-1984. Environ Health Perspect 2007; 115:1747-52

24. Post RE, Mainous AG 3rd, Diaz VA, Matheson EM, Everett CJ. Use of the nutrition facts label in chronic disease management: results from the National Health and Nutrition Examination Survey. J Am Diet Assoc 2010;110:628-32.

25. Starling AP, Umbach DM, Kamel F, Long S, Sandler DP, Hop- 
pin JA. Pesticide use and incident diabetes among wives of farmers in the Agricultural Health Study. Occup Environ Med 2014;71:629-35.

26. Agarwal A, Prajapati R, Singh OP, Raza SK, Thakur LK. Pesticide residue in water: a challenging task in India. Environ Monit Assess 2015;187:54.

27. Son HK, Kim SA, Kang JH, Chang YS, Park SK, Lee SK, et al. Strong associations between low-dose organochlorine pesticides and type 2 diabetes in Korea. Environ Int 2010;36:410-4.

28. Ritter R, Scheringer M, MacLeod M, Schenker U, Hungerbuhler K. A multi-individual pharmacokinetic model framework for interpreting time trends of persistent chemicals in human populations: application to a postban situation. Environ Health Perspect 2009;117:1280-6.

29. Sharma BM, Bharat GK, Tayal S, Nizzetto L, Cupr P, Larssen T. Environment and human exposure to persistent organic pollutants (POPs) in India: a systematic review of recent and historical data. Environ Int 2014;66:48-64.

30. Azandjeme CS, Bouchard M, Fayomi B, Djrolo F, Houinato D, Delisle $\mathrm{H}$. Growing burden of diabetes in sub-saharan Africa: contribution of pesticides? Curr Diabetes Rev 2013;9:437-49.

31. Bedi JS, Gill JP, Aulakh RS, Kaur P. Pesticide residues in bovine milk in Punjab, India: spatial variation and risk assessment to human health. Arch Environ Contam Toxicol 2015;69:230-40.
32. Bedi JS, Gill JP, Aulakh RS, Kaur P. Occurrence and spatial distribution of pesticide residues in butter and ghee (clarified butter fat) in Punjab (India). Environ Monit Assess 2016;188:100.

33. Tuomi T. Type 1 and type 2 diabetes: what do they have in common? Diabetes 2005;54 Suppl 2:S40-5.

34. Sladek R, Rocheleau G, Rung J, Dina C, Shen L, Serre D, et al. A genome-wide association study identifies novel risk loci for type 2 diabetes. Nature 2007;445:881-5.

35. Lee DH, Lee IK, Jin SH, Steffes M, Jacobs DR Jr. Association between serum concentrations of persistent organic pollutants and insulin resistance among nondiabetic adults: results from the National Health and Nutrition Examination Survey 19992002. Diabetes Care 2007;30:622-8.

36. Lee DH, Lee IK, Song K, Steffes M, Toscano W, Baker BA, et al. A strong dose-response relation between serum concentrations of persistent organic pollutants and diabetes: results from the National Health and Examination Survey 1999-2002. Diabetes Care 2006;29:1638-44.

37. Lee DH, Lee IK, Steffes M, Jacobs DR Jr. Extended analyses of the association between serum concentrations of persistent organic pollutants and diabetes. Diabetes Care 2007;30:1596-8.

38. Padmanabhan V, Cardoso RC, Puttabyatappa M. Developmental programming, a pathway to disease. Endocrinology 2016; 157:1328-40. 